\title{
PRÁTICAS DE LEITURA E ESCRITA EM SALA DE AULA UTI- LIZANDO GÊNEROS DA ESFERA RELIGIOSA: A PARÁBOLA
}

Gleice REIS

Lúcia Deodata dos Santos REIS ${ }^{2}$

Lucilene MESQUITA ${ }^{3}$

Sandra Emanoeli de B. SILVA

\begin{abstract}
RESUMO
Esta pesquisa se propõe a fazer um estudo sobre práticas de leitura e escrita em sala de aula utilizando gêneros da esfera religiosa, mais especificamente, a parábola. O propósito central desse artigo é abordar a importância do uso dos gêneros textuais e discursivos na sala de aula por meio das sequências didáticas, com base em pesquisas de alguns autores, como: Koche, (2014) Passarelli (2012) Sant'Anna (2010) Bazerman (2006) e Bakhtin que é citado por todos esses em suas obras. O estudo revela que os gêneros discursivos são essenciais para o ensino e aprendizado da língua, em virtude disso foi abordado sobre o gênero religioso, o qual está presente na sociedade brasileira de forma significativa. Foi escolhido para análise o gênero Parábola, pois o mesmo se evidencia como grande suporte ao trabalho de sala de aula, possibilitando ao aluno a compreensão da língua oral e escrita.
\end{abstract}

Palavras-chave: Gênero Discursivo. Gênero Parábola. Sequência Didática.

\begin{abstract}
This research proposes to make a study about practices of reading and writing in the classroom using genres of the religious sphere, more specifically, the parable. the main purpose of this article is to address the importance of using textual and discursive genres in the classroom through didactic sequences, based on research by some authors, such as: Koche, (2014) Passarelli (2012) Sant'anna (2010) Bazerman (2006) and Bakhtin who is quoted by all these in his works. the study reveals that discursive genres are essential for the teaching and learning of the language, because of this it was approached about the religious gender, which is present in brazilian society in a significant way. The parabola genus was chosen for analysis, as it is evidenced as a great support to the work of the classroom, enabling the student to understand oral and written language.
\end{abstract}

Keywords: Discursive Genre. Genre Parabola. Didatic Sequence.

\begin{abstract}
1 Aluna do curso de Pós Graduação em Língua portuguesa e literatura da Faculdade Esamaz 2017/e-mail: gleicereis25@gmail.com.
\end{abstract}

2 Aluna do curso de Pós Graduação em Língua portuguesa e literatura da Faculdade Esamaz2017/e-mail: lucia777@ gmail.com.

3 Aluna do curso de Pós Graduação em Língua portuguesa e literatura da Faculdade Esamaz 2017/ e-mail: mes- quista_lucilene@yahoo.com. br.

4 Aluna do curso de Pós Graduação em Língua portuguesa e literatura da Faculdade Esamaz 2017- e-mail: sandraemanoeli@yahoo.com.br.
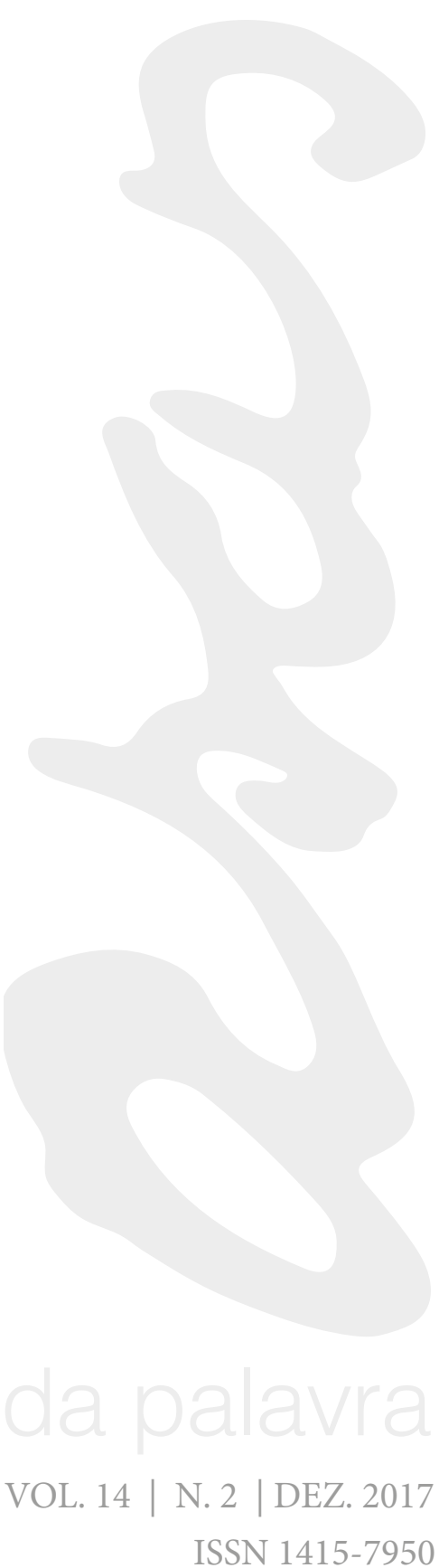


\section{INTRODUÇ̃̃O}

O presente trabalho tem como tema as práticas de leitura e escrita em sala de aula utilizando gêneros discursivos, pois se sabe que a fala e a escrita são retratadas no cotidiano por meio dos inumeráveis gêneros textuais e orais presentes no contexto social, e um desses gêneros é o religioso. Em virtude disso, a delimitação do tema proposto é o estudo da Parábola, gênero discursivo religioso muito conhecido nos textos bíblicos.

A problemática desse estudo se deu diante da dificuldade dos alunos em interpretar os textos orais e escritos o que é prejudicial para sua formação acadêmica, social e pessoal, esta afirmação pode ser comprovada pelas baixas notas em redação e língua portuguesa no Exame Nacional do Ensino Médio (ENEM) ${ }^{5}$, problema este trazido desde o ensino fundamental, por este motivo, busca-se neste trabalho apresentar e responder por meio da sequência didática como utilizar o gênero religioso para o aprendizado da leitura e escrita do aluno do $9^{\circ}$ ano?

O Brasil, apesar de ser um estado laico, é incontestavelmente religioso, pois $79 \%$ da população afirma seguir alguma religião ${ }^{6}$. Nas escolas, isso é notado nos grupos de conversas, nas características religiosas como vestimentas, objetos, palavreado que os próprios alunos deixam transparecer. Especificamente, analisaremos o gênero discursivo parábola e suas características, que é um gênero do tipo narrativo, o qual estimulará a criação textual e oralidade do discente.

O público alvo para aplicação da sequência didática serão os alunos do $9^{\circ}$ ano do ensino fundamental, pois se acredita que trazer esse tema pra sala de aula é uma forma de aproximar o aluno de sua realidade linguística, além de levá-lo ao entendimento textual e o respeito às diversidades religiosas.

Este trabalho se torna relevante para a construção de estratégias de ensino por meio da sequência didática criada pelos professores com o objetivo de levar o aluno ao desenvolvimento da leitura e escrita por meio dos gêneros discursivos presentes no cotidiano da sociedade. Para isso apoiamo-nos nos teóricos Bazerman (2006), Koche, (2014), Marcuschi (Sem Data) Passarelli (2012) e Sant'Anna (2010).

\section{O USO DOS GÊNEROS TEXTUAIS E DISCURSIVOS NA SALA DE AULA}

O uso dos gêneros textuais e discursivos na sala de aula constitui um recurso espetacular para ensinar os alunos a entenderem e compreenderem as ações decursivas que estruturam nossa sociedade. Os gêneros são inumeráveis, incontáveis, por isso, que o professor tem uma enorme gama de assuntos para se trabalhar, em vista disso Marcuschi diz:

5 INEP- Consulta publica Enem 2017 no site do Ministério da Educação

6 Fonte encontrada na matéria jornalística do G1: http:// g1.globo.com/mundo/noticia/2015/05/de-cada-10-brasileiros-8-dizem-ser-religiosos-diz-pesquisa-internacional. html

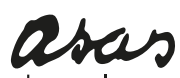

No entanto, mesmo apresentando alto poder preditivo e interpretativo das ações humanas em qualquer contexto discursivo, os gêneros não são instrumentos estanques e enrijecedores da ação criativa. Caracterizam-se como eventos textuais altamente maleáveis, dinâmicos e plásticos. Surgem emparelhados a necessidades e atividades socioculturais, bem como na relação com inovações tecnológicas, o que é facilmente perceptivel ao se considerar a quantidade de gêneros textuais hoje existentes em relação a sociedades anteriores à comunicação escrita. (MARCUSCHI, p.1) ${ }^{7}$

Bazerman (2006) diz que os gêneros que atuam em sala de aula são mais do que uma repetição ritual de preposições padronizadas.

Para Marcuschi ${ }^{8}$ os gêneros textuais estão vinculados à vida cultural e social e contribuem para organizar as atividades comunicativas. Sendo assim, é mais um motivo que eles devem ser trabalhados em sala de aula, pois os Parâmetros Curriculares Nacionais (1999) recomendam que os gêneros textuais sejam usados no ensino 
da língua portuguesa.

Passarelli (2012) ressalta a importância dos domínios discursivos serem trabalhados em sala de aula, os quais não englobam um gênero único, mas originam outros gêneros que são produzidos dentro de cada domínio discursivo por necessidade cultural e comunicativa. A autora ainda chama a atenção para que se ensine ao aluno que todo gênero é produzido para determinada sociedade e dentro dela, para isso, a mesma compartilha um exercício que costuma praticar com seus alunos para fixação do ensino sobre o tema. A autora diz:

Koche (2014), semelhante aos outros autores, também afirma que os gêneros textuais são o meio que ocorre as interações sociais, ligados a pratica social, cada indivíduo escolhe o gênero que vai usar para se comunicar em sociedade. Concernente a isso a autora diz:

A escolha do gênero textual depende da intenção do sujeito e da situação sociocomunicativa em que está inserido: quem ele é, para quem escreve, com que finalidade e em que contexto histórico ocorre a Comunicação. (KOCHE, 2014, p.11)

Os gêneros são de suma importância nas escolas como método de aprendizagem da leitura e escrita, já que a interação social ocorre por meio dos gêneros, ou seja, cada grupo social utiliza gêneros textuais específicos dotados de intencionalidade. Em vista disso (SANT'ANNA, 2010) diz que no âmbito religioso o gênero literário Parábola é comumente usado pelos integrantes deste grupo social, pelo fato deste gênero ter o tom menos moralizante e mais didático, servindo assim, para ensinar os princípios religiosos aos fiéis. Por conta disso, falaremos sobre a importância dos gêneros religiosos nas aulas de língua portuguesa e as principais características deste gênero.

\section{GÊNEROS RELIGIOSOS E SUA IMPORTÂNCIA NAS AULAS DE LÍN- GUA PORTUGUESA.}

Os gêneros dos discursos religiosos são marcados por uma forte ideologia e estão presentes no cotidiano do aluno brasileiro. Muitos alunos já tiveram contanto com este gênero por vários suportes como programas televisivos, e-mail, redes sociais, rádios, panfletos, jornais, nos templos das religiões etc. Daí sua importância em ser estudado em sala de aula, pois atualmente o discurso religioso está em pauta no mundo todo gerando muitas vezes conflitos e dúvidas.

Levando em consideração a população brasileira que em sua maioria é cristã, católica ou evangélica, não é difícil perceber que nas escolas brasileiras os alunos pertencem a alguma religião e têm contato direto com o gênero textual discursivo do qual faz parte, por este motivo, o professor não poderá desprezar esse contexto relacional do discente religioso ou não. Em relação a esta realidade Bazerman diz que "os alunos que trazem consigo seus próprios mapas de lugares e desejos comunicativos que lhes são familiares, vão se beneficiar dos sinais emitidos por aquelas pessoas já familiarizados om o novo cenário acadêmico.” (BAZERMAN, 2006, p. 24.)

Não se trata de uma aula de religião, não precisa o professor ser religioso ou tentar convencer os alunos de que uma religião é melhor do que a outra. Mas se trata de uma aula de português, onde os docentes e discentes não podem desprezar que existe esse gênero e ele precisa ser discutido em sala de aula.

\section{A PARÁBOLA}

\footnotetext{
A parábola é um gênero literário que tem como principal função o ensina-

A parábola é um gênero literário que tem como principal função o ensina-
mento moral e ético e por vezes religioso, ou seja, sua narração sempre contém um
}

7 Marcuschi, Luiz Antônio, Gêneros textuais1: definição e funcionalidade, encontrado em: https://edisciplinas.usp.br/mod/ resource/view.php?id=75828, .

8 Marcuschi, Luiz Antônio, Gêneros textuais1: definição e funcionalidade, encontrado em: https://edisciplinas.usp.br/mod/ resource/view.php?id=75828, . 
ensinamento ou esclarecimento do que se pretende ensinar. Este gênero tornou-se muito conhecido por causa dos evangelhos bíblicos contidos no Novo testamento. Jesus fez uso deste gênero como método de ensino ministrado ao povo, no templo e nas sinagogas para esclarecer os seus ensinamentos referindo-se a vida comum e aos interesses humanos, para patentear a natureza do seu reino e para experimentar a disposição de seus ouvintes (MATEUS 21. 45; Lucas 20. 19).

Segundo o dicionário bíblico ecumênico ${ }^{9}$ parábola é uma narrativa imaginada ou verdadeira, que se apresenta com o fim de ensinar uma verdade. Difere do proverbio, neste ponto, não é a sua apresentação tão concentrada como daquele, contém mais pormenores, exigindo menos esforço mental para se compreender e difere da alegoria, porque esta personifica atributos e as próprias qualidades, ao passo que a parábola nos faz ver as pessoas na sua maneira de proceder e de viver. E também difere da fábula, visto que aquela se limita ao que é humano e possível. Em vista disso Tavares explica:

Nas parábolas não se encontram os animais, essencialmente falando, como nas fábulas, nem os seres inanimados como nos apólogos. Entram apenas acidentalmente, pois a medida direta da parábola é o homem e sua destinação transcendente. (TAVARES, 1974, p. 178, apud ESTEVÃO, Adriana Gisele, 2016, p.50.) ${ }^{10}$

Segundo (SANT'ANNA, 2010) a etimologia da parábola se deu na Grécia e seu significado refere-se à comparação.

O nome parabolé deriva do verbo paraballo que, por sua vez, é uma forma composta dos seguintes segmentos: a) o prefixo pará que significa, em português, lado a lado, ao lado de, ao longo de, e b) ballo, verbo cujo significado pode ser traduzido para o português como jogar, trazer, colocar. A composição resulta, então, em colocar lado a lado com, manter ao lado, jogar para. (SANT'ANNA, 2010, p. 15)

Sant'Anna (2010) ainda adverte que o termo Parábola além do estudo linguístico é também usado em outros ramos da ciência como na Matemática, na Astronomia e Geometria. Mas somente na literatura ela apresenta o significado de comparação. Este significado grego clássico remete-se a retorica onde o orador pretende por meio da comparação (parábola) convencer seus ouvintes, no mesmo sentido as parábolas de origem latina tinham como objetivo a persuasão dos ouvintes. Se na retórica grega e latina a parábola tinha a função de persuadir, (SANT'ANNA, 2010) diz que nos textos épicos a parábola se apresenta como similitude (semelhança), também o autor faz uma comparação entre a parábola e a fabula, já que ambos são textos narrativos curtos e simples de alegoria, porém a distinção entre elas é "a animização dos animais [...] Na parábola, [...] não há ocasião para esse tipo de recurso de diálogos entre humanos e animais irracionais". (SANT'ANNA, 2010, p 223). Não há como confundir as narrativas, apesar de fábula e Parábola serem semelhantes, suas diferenças são expressivas. As principais características abordadas por (Sant'Anna, 2010) foram que as parábolas possuem temas variados, de caráter moralizante, universal e atemporal, ou seja, essas narrativas não estão presas ao tempo, a uma determinada região, podendo ser utilizada em vários contextos históricos e atuais. Os espações não são definidos geograficamente, são lugares comuns a qualquer parte do mundo,

9 Dicionário bíblico ecumênico, ed. Didática Paulista o tempo não marado cronologicamente. E uma narrativa curta em média 150 a 200 palavras com presença da moral da história quase sempre implícita. Os personagens são sempre seres humanos, e sem nomes próprios o que caracteriza a presença do mimetismo, ou seja, os personagens não são caracterizados psicologicamente nem individualizados para não serem identificados, o público ouvinte precisa se identificar, por isso são usados termos gerais como: Lavradores, fazendeiros, juízes, servos, 
pais etc.

A linguagem é da língua formal e conativa, a qual procura convencer o leitor ou ouvinte, uso abundante de metáforas e comparações, presença de adjetivação constante, predomínio dos verbos no pretérito perfeito e imperfeito, (mundo narrado/ plano ficcional)

Diante do conhecimento sobre os gêneros discursivos do âmbito religioso, apresentaremos uma sequência didática para explorar este assunto dentro de sala de aula.

A parábola tem como principal função o ensino, e algumas narrativas e exercem a função de ensino de valores espirituais. O exemplo tem as parábolas de Jesus Cristo que exerciam a função de simples lição de moral, outras repassavam uma profunda verdade espiritual. Em vista disso Sant'Anna (2010, p 236) diz: “O tom menos moralizante e mais didático distintivo da parábola permite-lhe funcionar com mais eficácia no processo de ensino aprendizagem, além de funcionar como instrumento de confronto nas relações interpessoais."

Os exemplos de parábolas de Jesus que cumprem função de ensino de acordo com (SANT'ANNA, 2010) são: Parábola do joio nomeia do trigo (Mateus t13. 24-30), a parábola do fermento (Mateus 13: 33-35), A parábola do tesouro e da perola (Mateus 13: 44-46), a parábola da rede (Mateus 13: 47-48) a parábola do devedor implacável (18: 23-24), a parábola do operário da vinha (Mateus 20:1-15) e a parábola das dez virgens (Mateus 25:1-12).

Apesar de o simples fato de contar parábolas não seja um ato religioso, o ato de conta-las foi difundida entre as tradições religiosas com a finalidade de ajudar os indivíduos a superarem obstáculos ao seu crescimento, a sua realização espiritual.

Segundo (SANT'ANNA, 2010) Uma das funções deste gênero no âmbito religioso é justamente é o confronto e encorajar reflexões intrapessoais e autoexames com o intuito de levar o ouvinte encarasse a justiça própria, a intelectualidade, a estultícia como atitudes indesejáveis.

Pode-se concluir então que a função das parábolas como elemento narrativo pertencente ao gênero religioso literário e servem ao discurso de confronto, didático religioso.

Como este gênero engloba a tipologia narrativa e possui características literárias pode ser comparado a outros tipos de texto narrativos como a Fabula, por se tratarem de textos que levam a uma reflexão em virtude de seu caráter moralizante sendo usado para produção de textos orais como contação de história e textos escritos.

\section{SEQUÊNCIA DIDÁTICA - CONSIDERAÇÕES TEÓRICAS}

A sequência didática é um recurso metodológico para se trabalhar os gêneros discursivos em sala de aula. Para Dolz, Noverraz e Schneuwly:

Uma sequência didática tem, precisamente, a finalidade de ajudar o aluno a dominar melhor um gênero de texto, permitindo-lhe, assim, escrever ou falar de uma maneira mais adequada numa dada situação de comunicação. O trabalho escolar será realizado, evidentemente, sobre gêneros que o aluno não domina ou o faz de maneira insuficiente; sobre aqueles dificilmente acessíveis, espontaneamente, pela maioria dos alunos; $e$ sobre aqueles públicos e não privados. As sequências didáticas servem, portanto, para dar acesso aos alunos a práticas de linguagem novas ou dificilmente domináveis. (DOLZ, NOVERRAZ, SCHNEUWLY, 2010, p. 83).
10 ESTEVÃO, Adriana Gisele, o gênero discursivo parábola na prática de sala de aula: uma proposta de didatização, 2016, p50. Dissertação apresentada à Universidade Estadual de Maringá, como requisito parcial para a obtenção do título de Mestre em Letras, área de concentração: Estudos Linguísticos.

Conforme afirma Bakhtin, gêneros são formas relativamente estáveis de enunciados e, ainda para este autor, nós só nos comunicamos, seja falando ou escre- 
vendo, por meio dos gêneros do discurso.

Portanto, partindo-se desse pressuposto, o estudo dos gêneros torna-se imprescindível para uma melhor compreensão do estudo da língua dentro dos processos de leitura, escrita e oralidade.

Assim, surge a sequência didática que se trata de um importante recurso metodológico para o estudo dos gêneros, pois a SD é uma sistematização de atividades organizadas a partir de um gênero oral ou escrito, levando em consideração a função social deste gênero e o que de significativo pode trazer para o aprendizado dos alunos.

A sequência didática de acordo com (DOLZ, NOVERRAZ e SCHNEWLY 2010) deve ser desenvolvida em quatro etapas que são: apresentação da situação; produção inicial; módulos e produção final. Na primeira etapa é feita uma sondagem do conhecimento prévio do aluno acerca do gênero proposto e leitura de textos daquele gênero para apropriação das características e elementos composicionais do gênero, função social, meios de suporte para divulgação do gênero, público-alvo e outras questões importantes para conhecimento do gênero apresentado.

Na segunda etapa, é desenvolvida uma atividade de produção, seja ela oral ou escrita, para que se possa analisar o que os alunos já conhecem do gênero proposto já que a partir disso o professor poderá constatar as capacidades já desenvolvidas pelos alunos.

Na terceira etapa serão desenvolvidas atividades de observação e análise de textos do gênero escolhido e tarefas de produção de textos, sejam orais ou escritos.

A última etapa é a produção final que dá ao aluno a oportunidade de colocar em prática as características e instrumentos apreendidos sobre o gênero em estudo.

\section{Gênero Textual: Parábola \\ Público Alvo: $9^{\circ}$ ano \\ Objetivos: Capacitar o aluno a compreender o gênero parábola. Módulo 1- Apresentação do gênero: Parábola Duração: 1 aula}

Nesta primeira aula, será instigado nos alunos o seu conhecimento prévio sobre o gênero parábola, e comentado sobre conceito, toda a estrutura do gênero, finalidade do gênero, onde podemos encontrar etc.

a) A todo o momento, em nossa vida, estamos aprendendo e ensinando, pois todas as pessoas têm algo para compartilhar. No entanto, há pessoas com uma enorme facilidade para compartilhar ensinamentos, usando historinhas para transmitir lições de vida e fazendo isso de maneira extraordinária. Quem de vocês conhece alguém assim? Vocês já ouviram essas historinhas? Onde? Alguém consegue contar uma?

b) Como são essas histórias que nos passam ensinamentos? Como são os personagens? E o nome delas, como elas são chamadas?

\section{Módulo 2- Leitura do gênero Duração: 2 aulas}

a) Essas histórias nos trazem grandes lições! Agora leremos uma história e vamos muita atenção e digam se já a ouviram em algum lugar.

Texto 1. Em resposta, disse Jesus: "Um homem descia de Jerusalém para Jericó, quando caiu nas mãos de assaltantes. Estes lhe tiraram as roupas, espancaram-no e se foram, deixando-o quase morto. Aconteceu estar descendo pela mesma estrada um sacerdote. Quando viu o homem, passou pelo outro lado. E assim também um levita; quando chegou ao lugar e o viu, passou pelo outro lado. Mas um samaritano, estando de viagem, chegou onde se encontrava o homem e, quando o viu, teve piedade dele. Aproximou-se, enfaixou - lhe as feridas, derramando nelas vinho e óleo. Depois o colocou sobre o seu próprio animal, levou-o para uma hospedaria e cuidou dele. No 
voltar, pagarei todas as despesas que você tiver'. 'Qual destes três você acha que foi o próximo do homem que caiu nas mãos dos assaltantes'? - 'Aquele que teve misericórdia dele', respondeu o perito na lei'. Jesus lhe disse: 'Vá e faça o mesmo'. Lucas 10: $30-37$ lugar.

Perguntar aos alunos se alguém já leu ou ouviu algo parecido em algum

a) É possível que se lembrem da igreja. Iniciar uma discussão para se chegar ao nome do gênero.

b) O texto lido passa uma moral também, assim como a fábula, não é mesmo? Mas nós podemos dizer que se trata de uma fábula? Por quê? Alguém sabe o nome dado a esses textos?

c) Temos então uma parábola! Alguém já havia ouvido esse nome antes?

d) Agora vamos fazer uma questão para refletir sobre a temática do texto:

Questão: Conforme interpretação da parábola $\mathrm{O}$ bom samaritano, marque a resposta certa:

( ) A parábola incentiva o desrespeito ao próximo.

( ) A parábola incentiva a intolerância e o preconceito à diversidade religiosa.

( ) A parábola mostra que devemos ajudar as pessoas independentemente das diferenças.

( ) A parábola em questão não tem nenhuma relação com o contexto atual.

e) O exemplo lido é do âmbito religioso, mas vocês sabiam que esses textos não existem somente com a temática religiosa? Eu tenho aqui outro texto para ler com vocês. Vamos lá?!

\section{Retratar a paz}

Um rei queria adquirir para o seu palácio um quadro que representasse a paz. Para isso, convocou artistas de diversas partes do mundo e lançou um concurso por meio do qual seria escolhido o tal quadro e premiado o seu autor.

Logo começaram a chegar ao palácio quadros de todo tipo. Uns retratavam a paz através de lindas paisagens com jardins, praias e florestas; outros a representavam através de arco-íris, alvoradas e crepúsculos.

O rei analisou todos os quadros e parou diante de um que retratava uma forte tempestade com nuvens pesadas, redemoinhos de ventos e uma árvore arqueada abrigando, dentro de seu tronco, um pássaro que dormia tranquilamente.

Diante de todos os participantes do concurso, o rei declarou aquele quadro da tempestade o vencedor do concurso. Todos ficaram surpresos, e alguém protestou dizendo:

-Mas... Majestade! Esse quadro parece ser o único que não retrata a paz!

Nesse momento o rei respondeu com toda convicção:

-O pássaro dorme tranquilamente dentro do tronco apesar da tempestade lá fora. Esta é a maior paz que se pode ter: a paz interior.

Paz não é a ausência de agitação no ambiente em que vivemos, mas o estado de tranquilidade interior que cultivamos diante das tempestades da vida.

f) E então? O que vocês acharam, é parecido ou não com o primeiro? Por quê? O que eles têm em comum?

(A partir desta indagação ir enumerando com os alunos as características do gênero).

g) Vocês já devem ter percebido que iremos estudar a parábola. Passo a passo vamos estudar as características e os elementos que a compõem para, no final, produzirmos uma coletânea de parábolas. Vamos lá?

h) Só para relembrarmos, quem é capaz de me explicar o que é uma parábo-

la?

(Iniciar uma discussão e dividir a sala em grupos) 
i) Agora vocês terão uma missão para tarefa de casa. Por meio de uma pesquisa, vamos buscar informações a respeito das parábolas!

Vamos pesquisar os seguintes pontos:

- O que é uma parábola?

- Como são os personagens de uma parábola?

- Quais são os tipos de parábolas que existem?

- Para que servem as parábolas?

- Onde as parábolas são usadas? Em que situações?

- Pesquise e escolha uma parábola para apresentar a seus amigos.

(Cada grupo ficará responsável pela pesquisa de um dos tópicos, na aula seguinte farão a socialização das informações encontradas, após a socialização distribuir cartolinas para que os alunos escrevam as características encontradas por eles e afixar os cartazes na sala).

j) Vimos que as parábolas tratam situações cotidianas de maneira metafórica. Entretanto, nem todas as parábolas possuem fácil entendimento, pois, muitas vezes, ao ilustrar uma situação, usam demasiadas palavras no sentido conotativo, ou seja, exigem uma interpretação que vai além da acepção da palavra no sentido literal. Vocês consideram que a maioria das parábolas, principalmente as bíblicas, são facilmente entendidas por todas as pessoas?

1) Por que vocês acham que as pessoas sentem dificuldades para inferir além do que está escrito?

\section{Modulo 3 - Produção do gênero \\ Duração: 3 aulas}

a) Nas aulas anteriores discutimos e estudamos um pouco mais sobre as parábolas, agora chegou a hora de botarmos a mão na massa e produzirmos nossos textos. Para isso, vamos formar, novamente, os grupos que formamos inicialmente.

(Organizar a formação dos grupos e, em seguida, escrever no quadro os pontos que devem ser anotados por todos os grupos para a elaboração das produções)

\section{Pontos:}

- Quais são os temas que podemos trabalhar em nossas parábolas?

- A quem se dirigirão nossas produções?

- Que forma assumirá nossas produções?

(Após essa discussão, cada grupo definirá seu tema para iniciar o processo de produção. Para auxiliar a produção, o professor deverá levar algumas parábolas para os grupos fazerem a leitura e servir como apoio para os alunos.É essencial, também, a mediação do professor nesse momento, já conduzindo os alunos a identificarem as marcas características dos gêneros, tais como expressões próprias, tempos verbais utilizados, personagens etc.)

A partir da Produção Inicial, o professor já sabe quais são as maiores dificuldades dos alunos com relação à produção do gênero, o que possibilita a intervenção do professor por meio de atividades que trabalhem as dificuldades encontradas.

a) Na aula anterior, produzimos nossas parábolas. Agora vamos apreciar as produções dos colegas.

b) Formar os grupos novamente e entregar as parábolas, distribuindo a produção de um grupo para o outro, para que o outro grupo leia e faça as atividades relacionadas ao conteúdo temático. Cada grupo fará a leitura silenciosa, discutirá entre si e responderá as seguintes questões:

- Sobre o que fala o texto?

- Ou seja, qual é o tema?

- Você acredita que a escolha desse tema foi por acaso ou os autores objeti- 
vavam transmitir algo para seus leitores?

- Esse tema tratado no texto lido é um tema importante somente hoje, no momento da produção ou é um tema que será de entendimento em qualquer época que for lido? Por quê?

(Quando todos os grupos terminarem as atividades, o professor deverá dar início à socialização das respostas).

c) Em seguida, cada representante de grupo fará a leitura em voz alta para toda a sala. Discutir sobre as respostas.

Durante o processo de leitura, fazer a medição para a compreensão daquilo que é concernente ao conteúdo temático de uma parábola. Após a discussão de todas as parábolas, sistematizar o que foi absorvido pelos alunos com relação ao conteúdo temático do gênero escrevendo no quadro um esquema com o que os alunos já aprenderam sobre o gênero.

Na nossa última aula, trabalhamos a respeito do conteúdo temático da parábola. Sem olhar nas nossas atividades passadas, vocês escreverão em seus cadernos tudo que vocês lembrarem e que acharem importante com relação ao conteúdo temático desse gênero.

d) Essa atividade deverá ser feita individualmente no caderno. Após todos responderem, fazer uma socialização rápida oralmente para ver se houve a fixação dos elementos mais importantes. Terminada essa introdução, novamente formar os mesmos grupos e distribuir uma nova parábola escrita por um grupo diferente da trabalhada pela equipe na aula anterior.

e) Que tal analisarmos agora como as parábolas se constroem?

Vamos ler a parábola para iniciarmos as atividades.

Escrever os enunciados das atividades no quadro. Os alunos discutirão em grupos, mas todos deverão produzir suas respostas nos cadernos:

- Podemos perceber que as parábolas são textos escritos em prosa, ou seja, são narrativas escritas em linhas retas, sem rimas. A história que vocês leram é uma narrativa curta. Por que vocês acham que as parábolas não são textos longos?

- As parábolas objetivam passar ensinamentos e assim como as fábulas apresentam sempre uma moral. Todavia, ao contrário das fábulas que quase sempre apresentam a moral explícita, nas parábolas o ensinamento moral apresenta-se diluído no texto, de maneira implícita. Você conseguiu identificar a moral no texto lido?

- Por falar em fábulas, vocês que já estão no $9^{\circ}$ ano, certamente já viram muitas delas e sabem, como já discutimos, que nelas os personagens são sempre animais. Já nos textos que estamos estudando, as parábolas, como são os personagens?

- Esses personagens possuem nomes próprios? Por quê?

- No texto que vocês estão lendo, é possível identificar com exatidão a data em que ele ocorreu? E o lugar onde se passou a história?

- Por que vocês acham que o tempo e o espaço são apresentados dessa maneira nas parábolas?

- E quanto ao título, vocês o consideram adequado à temática tratada na narrativa?

\section{Avaliação}

1) Antes de iniciar a produção, distribuir uma folha a cada aluno e pedir para que respondam aos seguintes pontos que servirão como um guia na produção do gênero. Após responder, a folha deve ser colada no caderno.

- O que é uma parábola?

- Sobre o que uma parábola pode falar, ou seja, que assuntos que podem ser abordados nesses textos?

- Como as parábolas se apresentam? Como é formado seu arranjo textual?

- Quais são as marcas linguísticas predominantes no gênero? 
2) Agora vamos colocar em prática tudo o que aprendemos sobre as parábolas. Durante nossas aulas, vocês já devem ter ficado pensando em um assunto que vocês gostariam de trabalhar, após ter lido e ouvido muitas parábolas! Escolham um tema, atentem às características que aprendemos e que acabamos de revisar.

3) Agora que produzimos os textos, precisamos saber se nossos interlocutores, ou seja, as pessoas que lerão nossos textos entenderão. Para isso, cada um vai ler o texto de um amigo e fará de conta que é o professor, indicando pontos que precisam ser revistos!

4) Distribuir uma produção para cada aluno, pois os alunos farão a revisão do texto dos colegas. Essa é uma atividade que exige muita dedicação, pois é necessário ler, reler e identificar o que não está bem claro e o que precisa ser melhorado!

Falar para os alunos os principais pontos a serem observados na correção:

- O texto está escrito de maneira formal ou informal?

-Todas as pessoas conseguirão entendê-lo ou há palavras que precisam ser substituídas?

- Você identificou o conteúdo temático dessa parábola? O assunto tratado é pertinente ao gênero?

- E a estrutura composicional está adequada a uma parábola?

- O tempo verbal corresponde aos propósitos comunicacionais de uma parábola?

- Há a presença de sentido conotativo, figuras de linguagem e adjetivos que colaboram para o efeito de sentido das parábolas?

- O texto está de acordo com a situação de produção?

- Há erros ortográficos?

(Mediar o processo de revisão e ir orientando cada aluno no decorrer da revisão do texto do colega).

Pedir que devolvam os textos aos colegas para que possam reescrevê-los e fazer os ajustes finais.

5) Após a atividade de reescrita, recolher os textos para realizar a correção final e, depois de realizada a correção final, o professor deverá entregar as produções aos alunos para que cada um possa fazer os ajustes necessários.

6) Em seguida, promover uma discussão em sala de aula acerca do projeto desenvolvido: -Vocês acham que esse estudo que realizamos será importante para a vida de vocês?

- Qual é a importância desse gênero na sociedade?

- Esse projeto foi importante para vocês? Ele aprimorou seus conhecimentos acerca da produção textual e outros aspectos da Língua Portuguesa?

7) Após a finalização das atividades, os textos deverão ser digitados, encadernados para que seja entregue uma cópia de cada coletânea de parábolas para cada aluno.

\section{CONSIDERAÇÕES FINAIS}

Diante da pesquisa realizada, conclui-se que os gêneros constituem um recurso rico que ajuda os alunos a localizarem suas ações discursivas em sociedade. Mas cabe aos professores ativares o dinamismo das aulas usando os diversos gêneros discursivos utilizando para esse objetivo as sequências didáticas que são ferramentas metodológicas que facilita o ensino e aprendizagem.

O trabalho com gênero aproxima alunos da sua realidade linguística, os professores podem usar as experiências dos alunos com os gêneros comuns às situações 
sociais dos discentes, por este motivo propusemos a sequência didática envolvendo o gênero religioso que é comum a todos independentemente de se ter religião ou não. Neste caso a parábola, gênero escolhido por ser tratar de texto narrativo, reflexivo e de cunho moralístico levando o aluno à reflexão do seu papel social.

Nesta perspectiva o aluno passa a ser um sujeito concreto e participativo, na construção do conhecimento, pois isso o estudo dos gêneros discursivo torna-se mais uma vez importantes para o aprendizado.

\section{REFERÊNCIAS}

BAZERMAN, Charles, HOFFNAGEL, Judith Chabilis e DIONÍSIO, Ângela Paiva. Gêneros, Agência e Escrita - São Paulo: Cortez, 2006.

BUYST, Ione. Homilia, partilha da palavra. São Paulo: Paulinas, 2001.

DOLZ, Joaquim E Schneuwly, B. Gêneros Orais e Escritos na Escola. Campinas: mercado das letras, 2010 .

ESTEVÃO, Adriana Gisele, O Gênero Discursivo Parábola na Prática de Sala de Aula: Uma Proposta de Didatização,. Dissertação apresentada à Universidade Estadual de Maringá, como requisito parcial para a obtenção do título de Mestre em Letras, área de concentração: Estudos Linguísticos. 2016. Disponível em: [https:// www.google.com.br.] Acesso em 0 4-04-2017.

FERRAZ, José, Homilética [A arte de preparar e pregar sermões], encontrado em: http://solascriptura-tt.org/Ide/Homiletica-JoseFerraz.htm. Acesso em 03/04/2017

KOCHE, Vanilda Salton; BENETTI, Odete Maria e MARINELLO, Adriane Fogali. Leitura e Produção Textual do Argumentar e Expor. 6.ed.- Petropolis. RJ: Vozes, 2014.

PASSARELLI, Lílian Maria Ghiuro. Ensino e correlação de produção de textos escolares, Editora: Cortez; Edição: 2012 (1 de janeiro de 2012)

SANT'ANNA, Marco Antônio Domingues. O Gênero da Parábola. [online] São Paulo.ed. UNESP,2010,316p.ISBN978853930439-4,Available from Scielo Books< HTTPS://books.scielo.org> Acesso em 03-04-2017 